\title{
Implementação de Rede Neural Artificial em Plataforma GPU Aplicada na Análise de Sentimentos em Textos *
}

\author{
Cristiano A. Kunas ${ }^{1}$, Leandro P. Heck ${ }^{1}$, Edson L. Padoin ${ }^{1}$ \\ ${ }^{1}$ Universidade Regional do Noroeste do Estado do Rio Grande do Sul (UNIJUI) \\ Santa Rosa - RS - Brasil \\ \{cristiano.kunas, leandro.h\}@sou.unijui.edu.br, \\ padoin@unijui.edu.br
}

\begin{abstract}
Resumo. Este artigo apresenta uma proposta de paralelização de uma Rede Neural Artificial em Plataforma GPU para aplicação na análise da polaridade de sentimentos expressado em textos elou postagens. Na implementação será utilizando Redes Neurais Recorrentes do tipo Long Short-Term Memory uma vez que Redes Neurais Artificiais podem auxiliar na extração automática de sentimentos ou sensação de sentenças. Com a aplicação da proposta em caso reais a partir do treinamento com o IMDb Review Dataset, que possui 50.000 registros espera-se uma boa precisão nos resultados.
\end{abstract}

\section{Introdução}

Diariamente, inúmeras informações circulam pela internet através de sites, blogs e redes sociais. O conteúdo presente vai desde análise e comentários de filmes até conversas e experiências dos seus usuários. Nesse sentido, usando os recursos tecnológicos podemos armazenar, recuperar e analisar uma enorme quantidade destes dados eficientemente. Uma questão é que esses dados não encontram-se estruturados de forma compreensível para um único sistema computacional. Assim sendo, a Inteligência Artificial (IA) pode ser aplicada para facilitar a compreensão desses dados, de tal maneira que possamos usar uma sentença em linguagem natural como entrada e extrair um conjunto de dados na saída [Brum 2015].

As opiniões são tão importantes para quase todas as atividades humanas que, sempre que precisamos tomar uma decisão, queremos ouvir as opiniões de outros [Liu et al. 2010]. Segundo Santos et al. (2010) "essa opinião informal ou formal, dependendo de onde foi postada, é de extrema importância, pois refletirá o sentimento sem censura do usuário". Com o crescimento das mídias sociais na Web e a rápida disseminação de textos online, torna impossível para qualquer ser humano ter conhecimento de todo conteúdo que o interessa em tempo hábil. Todavia, em algumas situações, apenas alguns pontos do texto são relevantes: sobre quem se fala, e se o que se fala é bom ou ruim [dos Santos 2017].

Indivíduos e organizações estão cada vez mais usando o conteúdo dessas mídias para a tomada de decisões. Porém, os sistemas computacionais ainda encontram grande dificuldade em compreender como os clientes se sentem em relação aos produtos e serviços de uma certa companhia. Desta forma, a utilização de uma Rede Neural Artificial (RNA) pode auxiliar na extração automática do sentimento ou sensação de sentenças, podendo refletir em ótimos resultados [Brum 2015]. Porém, dependendo do tamanho da base de dados utilizada no treinamento

\footnotetext{
*Trabalho desenvolvido com recursos do edital MCTIC/CNPq - Universal 28/2018 sob número 436339/2018-8 e do edital da VRPGPE bolsa PIBIC/UNIJUI.
} 
desta RNA, este processo tornar-se lento e um tanto custoso, onerando muito os processadores convencionais. Neste sentido, a utilização de Unidade de Processamento Gráfico (GPU) em conjunto com a computação paralela massiva disponível nestas arquiteturas, este processo é acelerado, proporcionando ganhos de desempenho.

A análise de sentimentos tem aspectos desafiadores à frente. Uma palavra de opinião que é considerada positiva em uma situação pode ser considerada negativa em outra situação. $\mathrm{O}$ processamento tradicional de texto considera que uma pequena mudança em dois bits de conteúdo não altera o sentido ou significado [Pang et al. 2002]. Mas, na análise de sentimentos, uma pequena mudança em dois bits de conteúdo muda de sentido ou significado, por exemplo, história é boa é diferente de história não é boa. O sistema processa-o analisando uma sentença de cada vez [Kalaivani and Shunmuganathan 2013].

Dentre as diferentes subáreas de estudo que o campo de análise de sentimento apresenta, a tarefa mais presente na literatura é a análise de polaridade de um documento. Neste sentido, este artigo apresenta uma proposta de utilização de uma RNA aplicada na análise da polaridade (positivo, negativo) do sentimento expressado através de textos e/ou postagens, tendo em vista que essa área está em constante crescimento e é de grande relevância para consumidores e organizações. O restante do trabalho esta organizado da seguinte forma. A Seção 2 discute os trabalhos relacionados. A Seção 3 apresenta a proposta de implementação da rede neural artificial. A Seção 4 apresenta a metodologia que será utilizada na implementação e o ambiente de execução para validar a proposta, seguidos das Conclusões e Trabalhos Futuros.

\section{Trabalhos Relacionados}

O conceito de análise de sentimentos e mineração de opinião foi introduzido pela primeira vez em 2003. Diversas técnicas foram usadas na mineração de opinião na história. O trabalho de Pang [Pang et al. 2002] aborda sobre o uso de técnicas de aprendizado de máquina supervisionadas para realizar a classificação de documentos não por tópico, mas por sentimentos gerais. Por exemplo, determinar se uma revisão é positiva ou negativa. No trabalho de Sharma et al. (2014), o objetivo é determinar a positividade ou negatividade das revisões de filmes no nível do documento. O sistema apresenta os resultados gerados, resumidos e úteis.

O artigo de [Kalaivani and Shunmuganathan 2013] compara três algoritmos de aprendizado de máquina supervisionados de Support Vector Machines (SVM), Naive Bayes e Kvizinhos mais próximos $(\mathrm{KNN})$ para a classificação de sentimento das críticas de filmes que contém 1000 críticas positivas e 1000 críticas negativas. Semelhante, o trabalho proposto por [Tripathi and Naganna 2015] apresenta uma abordagem para análise de sentimentos, comparando os diferentes métodos de classificação em combinação com vários esquemas de seleção de características. Ele analisou com sucesso os diferentes esquemas de seleção de características e seus efeitos na análise de sentimentos.

Na mesma linha, o artigo de [Hemalatha et al. 2013] destaca que o uso de emoticons como etiquetas barulhentas para dados de treinamento é uma maneira eficaz de realizar diferentes aprendizados supervisionados. Os algoritmos de aprendizado de máquina podem atingir alta precisão na classificação de sentimentos usando esse método.

Estes trabalhos comtemplam importantes contribuições no uso de Redes Neurais Artificiais para a cassificação de sentimentos. Seguindo a mesma linha de raciocínio, o presente trabalho propõe a paralelização de uma Rede Neural Artificial em arquitetura GPU, visando obter melhor desempenho, tanto no treinamento da rede, quanto no processamento das entradas. 


\section{Proposta}

Este trabalho propõe o desenvolvimento de uma Rede Neural Artificial paralela. O desenvolvimento do protótipo será organizado nas seguintes etapas. Na primeira, será composta uma base de dados rotulados entre positivo e negativo. Esta base será utilizada na sequência para o treinamento da RNA. A partir deste conjunto de dados, os parâmetros podem ser reajustados buscando melhorar a acurácia do algoritmo.

Em um segundo momento, pretende-se desenvolver a Rede Neural Recorrente do tipo Long Short-Term Memory (LSTM). As LSTM são uma variação da arquitetura de rede neural recorrente $(\mathrm{RNN})$ e possuem uma memória interna, de forma que as mesmas são capazes de "lembrar" características extraídas durante classificações anteriores por um período de tempo superior [Hochreiter and Schmidhuber 1997]. A LSTM é bem adequada para classificar, processar e prever séries temporais com intervalos de tempo de duração desconhecida [Olah 2015]. Estas redes são projetadas explicitamente para evitar problemas de dependência a longo prazo, objetivando a análise de polaridade de uma expressão. Na implementação será utilizado a Linguagem de programação Python e o framework Keras com TensorFlow-GPU no back-end, afim de possibilitar o uso da Plataforma GPU. Por fim, a versão paralela da rede neural poderá ser aplicada no reconhecimento de sentimentos possibilitando uma análise dos resultados.

\section{Metodologia}

Na etapa inicial - composição da base de dados rotulados entre positivo e negativo para utilizar no treinamento da rede neural - pretende-se avaliar a possibilidade de utilizar a base de dados IMDb Review Dataset elaborada no trabalho de [Maas et al. 2011]. Esta base possui uma coleção de 50.000 avaliações do IMDB, com mais que 30 críticas por filme. O conjunto de dados construído contém um número par de análises positivas e negativas o que possibilitará uma maior precisão do algoritmo desenvolvido.

A Rede Neural terá a função de analisar um texto de entrada (review) e predizer o quão positivo ou negativo é o sentimento expressado. Para que isso seja possível, o algoritmo irá carregar a base de dados rotulados e prepará-los para o treinamento. Após esta etapa, o conjunto de dados será dividido em duas partes, uma para treino $(80 \%)$ e outra para validação do modelo (20\%). Este percentual será avaliado para cada base de acordo com a precisão demandada. Na sequência, para o treinamento da rede neural, serão utilizadas técnicas de paralelismo, devido ao tempo e processamento que está etapa requer até que a rede consiga aprender e reconhecer os padrões. Desta forma, pode-se agilizar o processo de aprendizado da Rede Neural, proporcionando maior performance.

Alguns testes vem sendo desenvolvidos com uma versão do protótipo em um equipamento com o Sistema Operacional Linux Ubuntu 18.04.3 LTS com kernel 5.0.0-37-generic. O mesmo possui um processador Intel Core i7-9750 2.60GHz com 6 cores (12 threads), $16 \mathrm{~GB}$ de Memória RAM, uma acelerador NVIDIA GeForce GTX RTx 2060 com 6GB de GDDR6 e 1920 CUDA cores. Para a implementação do algoritmo está sendo utilizando a linguagem Python 3 e NVCC versão 10.1.105.

\section{Conclusões e trabalhos futuros}

Este trabalho apresenta uma proposta de utilização de uma Rede Neural Artificial Recorrente do tipo LSTM aplicada na análise da polaridade (positivo, negativo) do sentimento expressado através de textos e/ou postagens. 
Como trabalhos futuros, pretende-se implementar efetivamente a Rede Neural, tanto em arquitetura sequencial, quanto em paralela utilizando plataforma GPU. Na sequência, treinar a Rede Neural e aplicar na análise de sentimento afim de validar a proposta, analisando a execução dos algoritmos sequencial e paralelo, bem como os parâmetros envolvendo o paralelismo, compararando os tempos e desempenho de ambos. Também se cogita a utilização de outras bibliotecas e ferramentas de paralelismo para arquitetura GPU. Posteriormente, ampliar a base de dados rotulada com intuito de melhorar a acurácia da análise.

\section{Referências}

Brum, H. B. (2015). Análise de sentimentos para o português usando redes neurais recursivas. Monografia (Bacharel em Ciência da Computação), Universidade Federal do Pampa, Alegrete, Brazil.

dos Santos, I. P. P. (2017). Análise de sentimento usando redes neurais de convolução. Dissertação (Mestrado em Engenharia Eletrônica), Universidade do Estado do Rio de Janeiro, Rio de Janeiro, Brazil.

Hemalatha, I., Varma, G. S., and Govardhan, A. (2013). Sentiment analysis tool using machine learning algorithms. International Journal of Emerging Trends \& Technology in Computer Science (IJETTCS), 2(2):105-109.

Hochreiter, S. and Schmidhuber, J. (1997). Long short-term memory. Neural computation, 9(8):1735-1780.

Kalaivani, P. and Shunmuganathan, K. (2013). Sentiment classification of movie reviews by supervised machine learning approaches. Indian Journal of Computer Science and Engineering, 4(4):285-292.

Liu, B. et al. (2010). Sentiment analysis and subjectivity. Handbook of natural language processing, 2(2010):627-666.

Maas, A. L., Daly, R. E., Pham, P. T., Huang, D., Ng, A. Y., and Potts, C. (2011). Learning word vectors for sentiment analysis. In Proceedings of the 49th annual meeting of the association for computational linguistics: Human language technologies-volume 1, pages 142-150. Association for Computational Linguistics.

Olah, C. (2015). Understanding lstm networks. URL http://colah. github. io/posts/2015-08Understanding-LSTMs.

Pang, B., Lee, L., and Vaithyanathan, S. (2002). Thumbs up?: sentiment classification using machine learning techniques. In Proceedings of the ACL-02 conference on Empirical methods in natural language processing-Volume 10, pages 79-86. Association for Computational Linguistics.

Santos, L. M., Esmin, A. A. A., Zambalde, A. L., and Nobre, F. M. (2010). Twitter, análise de sentimento e desenvolvimento de produtos: Quanto os usuários estão expressando suas opiniões? Prisma. com, (13):159-170.

Sharma, R., Nigam, S., and Jain, R. (2014). Opinion mining of movie reviews at document level. arXiv preprint arXiv:1408.3829.

Tripathi, G. and Naganna, S. (2015). Feature selection and classification approach for sentiment analysis. Machine Learning and Applications: An International Journal, 2(2):1-16. 